\title{
La discriminación racial en Europa y en España: una perspectiva multidimensional
}

\author{
Racial discrimination in Europe and Spain: \\ A multidimensional perspective
}

SANDRO SESSAREGO ${ }^{1}$

Resumen: Este artículo ofrece un análisis del derecho a la igualdad y a la no discriminación racial en las sentencias del Tribunal Europeo de Derechos Humanos y estudia las repercusiones que dicha jurisprudencia ha tenido en los pronunciamientos del Tribunal Constitucional español. Se presta especial atención a los casos relacionados con tres tipologías diferentes de discriminación racial: (1) agresiones racistas por parte de miembros de las fuerzas armadas públicas, (2) discurso de odio racista en los medios de comunicación y (3) la tutela de la diversidad cultural de los grupos minoritarios.

Los resultados se analizan a la luz del escenario cada vez más multicultural y multirracial que caracteriza la España contemporánea. En línea con dicha evaluación, este estudio ofrece una serie de reflexiones que apuntan a una interpretación más homogénea del derecho a la igualdad, tanto a nivel nacional como internacional.

Palabras claves: Discriminación racial, Tribunal Europeo de Derechos Humanos, Tribunal Constitucional de España, fuerzas armadas y de seguridad, discurso de odio.

\footnotetext{
${ }^{1}$ Rapoport Center for Human Rights and Justice, University of Texas at Austin. Institut Universitari de Drets Humans, Universitat de València.
} 
Abstract: This article offers an analysis of the right to equality and racial non-discrimination in the judgments of the European Court of Human Rights and studies the impact that said jurisprudence has had on the pronouncements of the Spanish Constitutional Court. Special attention is paid to cases involving three different typologies of racial discrimination: (1) racist attacks by members of the public armed forces, (2) racist hate speech in the media, and (3) protection of the cultural diversity of minority groups.

Results are analyzed in light of the increasingly multicultural and multiracial scenario that characterizes contemporary Spain. In line with this assessment, this study provides a series of reflections that point to a more homogeneous interpretation of the right to equality, both nationally and internationally.

Keywords: Racial discrimination, European Court of Human Rights, Spanish Constitutional Court, armed and security forces, hate speech.

Recibido: 20.5.2020 Aceptado: 22.6.2020

Sumario

\section{Introducción}

2. La jurisprudencia del TEDH sobre la discriminación racial

3. Las repercusiones de la jurisprudencia del TEDH sobre las sentencias del TC

\section{Conclusiones}




\section{Introducción}

Las dinámicas socioculturales que caracterizan la España contemporánea se encuentran en línea con los fenómenos de globalización e integración que actualmente afectan varias partes del continente europeo. Dichas dinámicas son mucho más marcadas en regiones que, por proximidad geográfica a países en vía de desarrollo económico o situaciones laborales relativamente ventajosas, han sido meta de los flujos migratorios de las últimas décadas (Abella Vázquez 2003, 135). Otros factores que también influyen de forma mayúscula en estos fenómenos transnacionales son los conflictos bélicos y la búsqueda de mejores condiciones de vida. De hecho, a lo largo de los últimos treinta años, España ha pasado de ser un país de emigración a un país de inmigración. En el año 1990 había en el país aproximadamente 250 mil extranjeros, en 2005 más de 3 millones (Briones Gómez 2007, 4), y en enero de 2017 este número llegó a cerca de los 4 millones y medio (Instituto Nacional de Estadística 2017).

El antropólogo Rafael Briones Gómez hizo un análisis en 2007 de la evolución de las dinámicas socioculturales del país y concluyó que, desde el fin de la época franquista, España había pasado «de una sociedad, cultural y religiosamente, casi homogénea y monocolor a otra plural o multicultural» (Briones Gómez 2007, 3). Este cambio puede generar, en algunos sectores de la población, actitudes de rechazo o intolerancia (Cea D'Ancona y Valles Martínez 2011, 367377). El miedo al extranjero, al diferente, al “otro", puede llevar a comportamientos prejuiciosos y, en algunos casos, a episodios racistas violentos de extrema gravedad.

El presente trabajo ha sido concebido dentro de estas dinámicas internacionales. En particular, se analizan las sentencias del Tribunal Europeo de Derechos Humanos (TEDH) relacionadas con este tema y los efectos que su jurisprudencia ha tenido en la doctrina del Tribunal Constitucional español (TC). Se examina, pues, el impacto que las sentencias del TEDH ejercieron en cuestiones relativas a asuntos de discriminación racial. 
En este sentido, se investiga la jurisprudencia del TC sobre temas relacionados con los comportamientos racistas de algunos miembros de las fuerzas públicas, el discurso racista que ha estado presente en algunos medios de información, y la tutela de la diversidad cultural de los grupos minoritarios. Estos tres aspectos, analizados en su conjunto, pueden ofrecer un cuadro bastante completo de las dinámicas jurídico-sociales que interesan a la relación entre Estado, sociedad y grupos minoritarios.

El comportamiento de las fuerzas armadas es un elemento vital para la integración de las minorías, porque sus miembros son representantes del Estado y tienen contacto diario con la población. Por otro lado, el discurso racista trasmitido en algunas ocasiones por determinados medios de información representa la imagen de las minorías que algunos grupos políticos o individuos quieren proyectar del "otro". Es entonces un aspecto igualmente importante para medir el nivel de integración y aceptación de dichos grupos por los demás miembros de la sociedad. Finalmente, en mi opinión, la jurisprudencia relativa a los casos de tutela de la diversidad cultural completaría el cuadro ofreciendo una visión de las acciones que los tribunales han querido impulsar para proteger a grupos que -al ser minoritarios- muchas veces no se encuentran en una situación de igualdad sustancial. Ese tipo de medidas, entonces, integran los aspectos anteriormente mencionados proveyendo así una perspectiva multidimensional de la evolución del principio de igualdad en un contexto cada vez más multicultural y multirracial.

El análisis comparativo de la doctrina del TEDH y del TC y, más concretamente, de la vinculación que el Alto Tribunal español tiene con respecto a las sentencias del Tribunal de Estrasburgo, puede contribuir a fortalecer una interpretación más homogénea $\mathrm{y}$ garantista del derecho a la igualdad y a la no discriminación racial a nivel nacional y europeo. 


\section{La jurisprudencia del TEDH sobre la discriminación racial}

Como pone en evidencia Rey Martínez (2012, 297), los episodios más comunes de discriminación racial en el ámbito europeo son las agresiones racistas por agentes de las fuerzas públicas, no sólo por el número de sentencias, sino también por la trascendencia de los sucesos implicados. En este contexto, una evolución importante en la doctrina del TEDH estuvo marcada por el voto particular del juez Bonello en la sentencia Anguelova c. Bulgaria de 13 de septiembre de 2002. En aquella ocasión, los demandantes eran unos gitanos que alegaban razones racistas detrás de la muerte de unos miembros de su comunidad bajo las dependencias de las fuerzas públicas nacionales de Bulgaria. En aquella circunstancia, sin embargo, la sentencia del Tribunal no asoció la muerte de las víctimas gitanas a un caso de discriminación racial (art. $14 \mathrm{CEDH}^{2}$ ) y, por esta razón, el magistrado Bonello disintió, indicando cuanto sigue en su voto particular (Abrisketa Uriarte 2015, 5):

Al hojear los anales de la Corte, un observador desinformado estaría justificado de concluir que, durante más de cincuenta años, la Europa democrática ha estado exenta de toda sospecha de racismo, intolerancia o xenofobia. La Europa que proyecta la jurisprudencia de la Corte es la de un remanso ejemplar de fraternidad étnica, en el que los pueblos de origen más diverso se unen sin angustia, prejuicio o recriminación. ${ }^{3}$

Este voto disidente sentó los fundamentos teóricos sobre los cuales la jurisprudencia del TEDH empezó a construir una doctrina

\footnotetext{
2 Art. 14 Convenio Europeo para la Protección de los Derechos Humanos y de las Libertades Fundamentales (CEDH): «El goce de los derechos y libertades reconocidos en el presente Convenio ha de ser asegurado sin distinción alguna, especialmente por razones de sexo, raza, color, lengua, religión, opiniones políticas u otras, origen nacional o social, pertenencia a una minoría nacional, fortuna, nacimiento o cualquier otra situación».

3 TEDH Anguelova c. Bulgaria 2002. Opinión particular del Juez Bonello, apartado 2. Traducción propia.
} 
más atenta a los fenómenos de discriminación racial, sobre todo en relación a episodios de violencia llevados a cabo por las fuerzas públicas (Möschel 2014, 151). La sentencia del Tribunal que, en este sentido, hizo historia es la del caso Nachova y otros c. Bulgaria de 6 de julio de 2005, que relaciona directamente la muerte de algunos miembros de la comunidad gitana a fenómenos de discriminación racial.

Esta vez, tras hacer suya la tesis del voto discordante del juez Bonello en la sentencia Anguelova c. Bulgaria, el TEDH afirmó en la sentencia Nachova yotros c. Bulgaria que en los casos de violencia en los cuales se alegue discriminación racial, las autoridades públicas tienen que investigar de manera efectiva los hechos y, en particular, tienen «el deber adicional de adoptar las medidas razonables para desenmascarar cualquier motivación racista en un incidente que implique el uso de la fuerza por los agentes estatales». Así que, en estas situaciones, «la carga de probar que no ha habido discriminación corresponde a las autoridades nacionales demandadas» (Rey Martínez 2012, 298).

En virtud de la importancia de la sentencia Nachova y otros $c$. Bulgaria, su doctrina suele ser reiterada por el TEDH en casi todos los casos posteriores parecidos: Bekos y Koutropoulos c. Grecia de 13 de diciembre de 2005, Ognyanova y Chocan c. Bulgaria de 23 de febrero de 2006, D.H. y otros c. República Checa de 13 noviembre de 2007,4 Jaloud c. Holanda de 20 de noviembre de 2014, etc. En el caso de España, vale la pena mencionar la sentencia B.S. c. España de 24 de julio de 2012, que condenó a España por racismo y tuvo como protagonista a la señora B.S., una mujer de origen nigeriano que ejercía la prostitución en la vía pública en la zona del Arenal, cercana a Palma de Mallorca. En este caso, la señora B.S. alegó, entre otros asuntos, haber sido golpeada por un policía con una porra que le

\footnotetext{
${ }^{4}$ Este caso es de particular interés porque no sólo fortalece la lógica de la inversión de la carga de la prueba, sino que, además, reconoce la validez de las estadísticas como elemento de prueba para decidir si una determinada práctica se puede considerar discriminadora. Véase Rey Martínez (2008).
} 
lastimó una mano y una rodilla, además de ser insultada con epítetos racistas. A lo largo de los varios juicios nacionales, la policía se resistió en diferentes ocasiones a llevar a cabo una verdadera investigación efectiva para indagar sobre la posible culpa de los agentes involucrados (TEDH B.S. c. España 2012, 8).

El TEDH apuntó claramente el principio de igualdad (art. 14 $\mathrm{CEDH})$ con especial atención al aspecto racial de la cuestión. En particular, los puntos 58 y 59 de la sentencia hacen una referencia explícita a las cuidadosas medidas de investigación que el Estado tiene el deber de implementar para descubrir potenciales episodios de violencia y discriminación racial relacionados al uso de la fuerza por autoridades públicas, como lo había establecido en la sentencia Nachova y otros c. Bulgaria:

58. La Corte considera que cuando las autoridades estatales investigan incidentes violentos, tienen la obligación adicional de tomar todas las medidas razonables para determinar si hubo motivos racistas y establecer si el odio o el prejuicio étnico pueden haber desempeñado un papel en los acontecimientos. Es cierto que probar la motivación racial será a menudo extremadamente difícil en la práctica. La obligación del Estado demandado de investigar los posibles matices racistas de un acto violento es una obligación de hacer todo lo posible y no es absoluta. Las autoridades deben hacer, según las circunstancias dadas, lo que sea razonable para reunir y asegurar las pruebas, explorar todos los medios prácticos para descubrir la verdad y adoptar decisiones plenamente razonadas, imparciales y objetivas, sin omitir los hechos sospechosos que puedan ser indicativos de violencia inducida por motivos raciales (véase, mutatis mutandis, Nachova y Otros c. Bulgaria [GC], núm. 43577/98 y 43579/98, § 160, TEDH 2005-VII).

59. Además, el deber de las autoridades de investigar la existencia de un posible vínculo entre las actitudes racistas y un acto de violencia es un aspecto de sus obligaciones 
procesales derivadas del Artículo 3 del Convenio, ${ }^{5}$ pero también puede considerarse implícito en sus responsabilidades en virtud del artículo 14 del Convenio de garantizar el respeto sin discriminación del valor fundamental consagrado en el Artículo $3{ }^{6}$

Otro tipo de discriminación relacionado con la raza es el discurso racista o de odio (del inglés hate speech) propagado por los medios de información (Esquivel Alonso 2016, 15-18). El problema principal que ha encontrado el TEDH a la hora de condenar este fenómeno es que muchas veces, en dicho contexto, el principio de no discriminación (art. $14 \mathrm{CEDH}$ ) choca con otras libertades tuteladas por el Convenio, en particular, las libertades de expresión e información (art. 10 $\left.\mathrm{CEDH}^{7}\right)$.

Uno de los casos clásicos que representan esta colisión es la sentencia del TEDH en Jersild $c$. Dinamarca de 23 de septiembre de 1994. En este juicio, el TEDH indicó que la sanción dictada por Dinamarca a la periodista Jersild, quien había trasmitido entrevistas hechas a miembros de una organización racista (Grønjakkerne, "los chaquetas verdes"), iba en contra del art. 10.1 CEDH. Las entrevistas transmitidas incluían frases de contenido extremadamente racista e intolerante, que podrían identificarse como discurso de odio. Sin embargo, el Tribunal concluyó que Jersild no estaba fomentando el odio, sino simplemente informando al público danés acerca de la

\footnotetext{
${ }^{5}$ Art. 3. CEDH: Nadie podrá ser sometido a tortura ni a penas o tratos inhumanos o degradantes.

${ }^{6}$ TEDH B.S. contra España (2012). Traducción propia.

${ }^{7}$ Art. 10. CEDH: «1. Toda persona tiene derecho a la libertad de expresión. Este derecho comprende la libertad de opinión y la libertad de recibir o de comunicar informaciones o ideas sin que pueda haber injerencia de autoridades públicas y sin consideración de fronteras. El presente artículo no impide que los estados sometan a las empresas de radiodifusión, de cinematografía o de televisión a un régimen de autorización previa. 2 . El ejercicio de estas libertades, que entrañan deberes y responsabilidades, podrá ser sometido a ciertas formalidades, condiciones, restricciones o sanciones, previstas por la ley, que constituyan medidas necesarias, en una sociedad democrática, para la seguridad nacional, la integridad territorial o la seguridad pública, la defensa del orden y la prevención del delito, la protección de la salud o de la moral, la protección de la reputación o de los derechos ajenos, para impedir la divulgación de informaciones confidenciales o para garantizar la autoridad y la imparcialidad del poder judicial».
} 
existencia en el país de este grupo racista y de sus ideas sobre la sociedad. El TEDH resaltó que las libertades de expresión y de información tienen un papel fundamental en una sociedad democrática. Por esta razón, según el Tribunal, los reporteros no sólo tienen el derecho sino también el deber de informar al público sobre cualquier tipo de opinión política, incluso sobre los puntos de vista de grupos minoritarios que tengan ideales divergentes de la mayoría o perspectivas racistas, siempre y cuando se limiten a reportar dichas opiniones y no a fomentarlas (cf. TEDH Jersild c. Dinamarca 1994, §31). Debido a que Jersild no había adoptado una postura racista a lo largo del reportaje y había transmitido dichas entrevistas manteniendo una posición neutral, el Tribunal amparó a la periodista de las sanciones penales aplicadas por Dinamarca.

La sentencia Jersild no fue apoyada por un voto unánime. Varios jueces se opusieron al fallo, indicando que la periodista habría tenido que distanciarse de manera mucho más explícita de los comentarios racistas de los Grønjakkerne (TEDH Jersild c. Dinamarca 1994, 25-30). Tales magistrados criticaron además la opinión mayoritaria del Tribunal, indicando que «es ciertamente difícil encontrar el equilibrio adecuado entre la libertad de prensa y la protección de los demás. Pero la mayoría [de este Tribunal] atribuye mucho más peso a la libertad de la periodista que a la protección de aquellos que tienen que sufrir el odio racista».

En otros casos, el TEDH parece haber otorgado un mayor peso al principio de igualdad y no discriminación de las minorías raciales, contrastando así de manera más concreta la supuesta libertad de expresión e información invocadas por grupos racistas (Kiska 2012, 108-137). Un caso importante en este sentido es la sentencia Norwood c. Reino Unido de 16 de noviembre de 2004. Este caso concierne la libertad de expresión e información invocada por un partido político derechista del Reino Unido, el British National Party, cuyo dirigente mostró públicamente una imagen ofensiva contra la comunidad musulmana. En este caso, el señor Norwood había pegado en la ventana de su apartamento una foto del ataque terrorista ocurrido en 
Nueva York el día 11 de septiembre de 2001. La foto contenía una reproducción de las Torres Gemelas en llamas y un mensaje que decía «Islam out of Britain. Protect the British people» («iFuera el islam de Gran Bretaña! ¡Proteged al pueblo británico!»). También se incluía el símbolo musulmán de la media luna dentro de una señal de prohibición. Esta imagen fue sucesivamente reportada por varios medios de comunicación nacionales (Quesada Alcalá 2015, 10).

El TEDH resolvió el caso señalando que los mensajes discriminatorios del British National Party, que vinculaban a un grupo religioso con el terrorismo, iban en contra de los principios de tolerancia, paz e igualdad del Convenio. Por esta razón, invocando el art. $17 \mathrm{CEDH}$ (abuso del derecho), ${ }^{8}$ el TEDH puso de manifiesto una postura según la cual "quedarían excluidos de la protección de la libertad de expresión los discursos claramente racistas» (Quesada Alcalá 2015, 11).

En relación con España, en la sentencia del TEDH Varela Geis $c$. España del 5 de marzo de 2013, el Gobierno nacional invocó ante el TEDH el art. 17 CEDH (con clara referencia a la sentencia Norwood) para que se condenara al Señor Varela Geis, dueño de una librería neonazi de Barcelona dedicada a la venta y distribución de libros negacionistas del Holocausto. Varela Geis, en cambio, intentó apelar y reivindicar los fallos emitidos aduciendo la privación de su plena capacidad de defenderse (art. $6 \mathrm{CEDH}$ ), así como la violación de su derecho a la libertad de pensamiento y expresión (arts. 9 y10 CEDH), relacionándolas con la sentencia Jersild.

El Tribunal reconoció que el derecho de Varela Geis a un proceso equitativo (art. $6 \mathrm{CEDH}$ ) había sido vulnerado, y no se pronunció sobre la invocada vulneración de sus derechos a la libertad de pensamiento y de expresión, fallando que «no procede examinar [...]

\footnotetext{
${ }^{8}$ Art. 17 CEDH: «Ninguna de las disposiciones del presente Convenio podrá ser interpretada en el sentido de implicar para un Estado, grupo o individuo, un derecho cualquiera a dedicarse a una actividad o a realizar un acto tendente a la destrucción de los derechos o libertades reconocidos en el presente Convenio o a limitaciones más amplias de estos derechos o libertades que las previstas en el mismo».
} 
si ha habido, en el presente caso, violación de los artículos 9 y $10 \mathrm{del}$ Convenio» (TEDH Varela Geis c. España 2013, 20). El TEDH, de esta manera, no profundizó en la colisión entre la prohibición de discriminación racial y las libertades alegadas. Al mismo tiempo, rechazó los argumentos del Gobierno que relacionaba las libertades reclamadas por Varela Geis con el abuso del derecho (art. $17 \mathrm{CEDH}$ ).

En varias ocasiones el TEDH ha afirmado que en una sociedad democrática es fundamental aceptar la existencia de diferentes perspectivas y opiniones políticas que, aunque puedan ser minoritarias o totalmente opuestas a la corriente de pensamiento principal, no se deben silenciar (TEDH Jersild c. Dinamarca 1994). La idea de que la diversidad enriquece la democracia no sólo se ha argumentado en el contexto de la libertad de pensamiento y de expresión; sino que además el TEDH ha utilizado este concepto en otros ámbitos, como en relación con la presencia de minorías étnicas y raciales en el territorio europeo. En estos contextos, entonces, el Tribunal de Estrasburgo se ha referido al pluralismo cultural, que representaría otro eje fundamental, igualmente importante, de una sociedad democrática sana. Por ejemplo, en la ya mencionada sentencia Nachova c. Bulgaria, el Tribunal se pronunció sobre los daños del racismo en la sociedad y clasificó claramente la diversidad cultural y étnica como elemento de riqueza de los sistemas democráticos:

La discriminación es tratar de manera diferente, sin una justificación objetiva y razonable, a personas en situaciones similares (véase Willis c. Reino Unido, núm. 36042/97, $\mathcal{S} 48$, TEDH 2002-IV). La violencia racial es una afrenta particular a la dignidad humana $y$, en vista de sus peligrosas consecuencias, exige de las autoridades una vigilancia especial y una reacción enérgica. Por esta razón, las autoridades deben utilizar todos los medios disponibles para combatir el racismo y la violencia racista, reforzando así la visión de la democracia de una sociedad en la que la 
diversidad no se percibe como una amenaza sino como una fuente de enriquecimiento. ${ }^{9}$

La idea de que los grupos minoritarios deben verse como elementos de riqueza democrática ha ido adquiriendo relevancia en la doctrina del TEDH. Unas sentencias emblemáticas en este sentido son las de Chapman c. Reino Unido (2001), Coster c. Reino Unido (2001), Beard c. Reino Unido (2001), Lee c. Reino Unido (2001) y Smith c. Reino Unido (2001). ${ }^{10}$ En todas ellas los demandantes eran familias gitanas que reclamaban, entre otros asuntos, la violación del principio de igualdad (art. $14 \mathrm{CEDH}$ ) por razones raciales, y el derecho al respeto a la vida privada y familiar (art. $8 \mathrm{CEDH}^{11}$ ), visto que nunca les fue concedido el permiso de vivir en caravanas en terrenos de su propiedad donde, por motivos urbanos y paisajísticos, no era posible instalar acampamientos nómadas.

En estos casos específicos, el TEDH no reconoció ninguna de las violaciones invocadas por las familias gitanas, pero puso en evidencia que los estados tienen el deber de reconocer las necesidades y estilos de vida de las minorías étnicas, no sólo para proteger la identidad de estas, sino además porque la presencia de diversidad cultural beneficia a toda la sociedad.

La Corte observa que puede decirse que existe un consenso internacional emergente entre los Estados Contratantes del Consejo de Europa que reconoce las necesidades especiales de las minorías y la obligación de proteger su seguridad,

\footnotetext{
${ }^{9}$ STEDH Nachova y otros c. Bulgaria (2005). Traducción propia.

${ }^{10} \mathrm{La}$ Gran Sala del TEDH dictó sentencia sobre todos estos casos por concernir todos a la instalación de caravanas gitanas en áreas no habilitadas. Véase también Bouazza Ariño (2003).

${ }^{11}$ Art. 8 CEDH: «1. Toda persona tiene derecho al respeto de su vida privada y familiar, de su domicilio y de su correspondencia. 2. No podrá haber injerencia de la autoridad pública en el ejercicio de este derecho sino en tanto en cuanto esta injerencia esté prevista por la ley y constituya una medida que, en una sociedad democrática, sea necesaria para la seguridad nacional, la seguridad pública, el bienestar económico del país, la defensa del orden y la prevención de las infracciones penales, la protección de la salud o de la moral, o la protección de los derechos y las libertades de los demás».
} 
identidad y estilo de vida [...], no sólo con el fin de salvaguardar los intereses de las propias minorías sino también de preservar una diversidad cultural de valor para toda la comunidad. ${ }^{2}$

Asimismo, recordando que el hecho de pertenecer a una minoría con costumbres distintas de los demás no implica ser inmune a las leyes, el Tribunal afirmó que dichas leyes podrían ser implementadas por la administración pública de manera que se tomaran en cuenta las diferencias culturales en cuestión de forma más flexible:

Aunque el hecho de pertenecer a una minoría con un estilo de vida tradicional diferente al de la mayoría no confiere inmunidad con respecto de las leyes generales destinadas a salvaguardar los bienes de la comunidad en su conjunto, como el medio ambiente, puede tener una incidencia en la manera en que se apliquen esas leyes [...] la posición vulnerable de los gitanos como minoría significa que se debe prestar cierta consideración especial a sus necesidades y a su diferente estilo de vida, tanto en el marco de planificación normativa pertinente como en la toma de decisiones en casos particulares. $^{13}$

De todas formas, aun reconociendo las peculiaridades culturales de la comunidad gitana, el TEDH en ninguna de estas sentencias les dio la razón a los demandantes. Sin embargo, hay que indicar que el voto de los magistrados no fue siempre unánime. Por ejemplo, en el caso Chapman c. Reino Unido, algunos jueces (Pastor Ridruejo, Tulkens, Stráznická, Lorenzen, Fischbach, Casadevall y, nuevamente, Bonello) disintieron de la sentencia votada por la mayoría en cuanto al art. $8 \mathrm{CEDH}$. Según ellos, sí hubo violación del respeto a la vida privada y familiar de los Chapman porque, entre otros elementos, en la práctica, no le fueron ofrecidas muchas alternativas viables a esta

12 TEDH Chapman c. Reino Unido (2001), Coster c. Reino Unido (2001), Beard c. Reino Unido (2001), Lee c. Reino Unido (2001) y Smith c. Reino Unido (2001). Traducción propia.

13 TEDH Chapman c. Reino Unido (2001). Traducción propia. 
familia. Según dichos magistrados, el art. 8 CEDH implicaría ofrecer oportunidades efectivas de disfrutar de la vida familiar y, por tanto, el Reino Unido habría violado el Convenio:

\begin{abstract}
Nuestra opinión es que el Artículo 8 de la Convención impone a las autoridades la obligación positiva de garantizar que los gitanos tengan una oportunidad práctica y efectiva de disfrutar de su derecho al respeto de su hogar y de su vida privada y familiar, de acuerdo con su estilo de vida tradicional [...]. Concluimos que ha habido una violación del Artículo 8 de la Convención. ${ }^{14}$
\end{abstract}

En cuanto a España, las afirmaciones del TEDH en la sentencia Chapman c. Reino Unido sobre la protección especial de las categorías vulnerables fueron retomadas en la sentencia Muñoz Díaz (STEDH Muñoz Díaz c. España 2009), más conocida en la sociedad española como el caso del «matrimonio gitano», que tuvo bastante cobertura en los medios de información nacionales (Berenguer Albaladejo 2010). La sentencia del TEDH en el caso Muñoz Díaz $c$. España del 9 de diciembre de 2009 condena al Estado español - por asuntos de discriminación racial— a pagar la pensión de viudedad a una ciudadana casada por el rito matrimonial gitano, no legalmente reconocido por el Estado. En particular, el Tribunal falló que España había violado la prohibición de discriminación racial (art. 14 CEDH) en relación al derecho al respeto de los bienes (art. 1, Protocolo I $\left.\mathrm{CEDH}^{15}\right)$.

En concreto, el TEDH indicó que la discriminación contra la señora Muñoz Díaz se dio porque en otras situaciones equivalentes la pensión de viudedad se había concedido, asumiendo la buena fe de la

\footnotetext{
${ }^{14}$ Ibídem.

${ }^{15}$ Art. 1. Protocolo I CEDH: «Toda persona física o jurídica tiene derecho al respeto de sus bienes. Nadie podrá ser privado de su propiedad sino por causa de utilidad pública $\mathrm{y}$ en las condiciones previstas por la ley y los principios generales del Derecho Internacional. Las disposiciones precedentes se entienden sin perjuicio del derecho que tienen los Estados de dictar las leyes que estimen necesarias para la reglamentación del uso de los bienes de acuerdo con el interés general o para garantizar el pago de los impuestos, de otras contribuciones o de las multas».
} 
viuda. Los precedentes alegados fueron dos casos de matrimonios nulos (art. 174 LGSS [Real Decreto Legislativo 8/2015]) y, sobre todo, el caso del precedente de la sentencia TC 199/2004, en el que se concedía la pensión a una viuda de un matrimonio católico no inscrito en el Registro Civil (Cremades García 2010, 337). Como reporta Rey Martínez (2012, 313), el Tribunal arguyó a favor de las demandas de la señora Muñoz Díaz basando su razonamiento en dos tipos de argumentos. Por un lado, los jueces indicaron que en varias ocasiones las autoridades españolas habían reconocido la validez de este matrimonio (libro de familia, el título de familia numerosa, la cartilla de seguridad social, etc.) y, por el otro, el Tribunal se apoyó en el tema étnico-racial, subrayando la importancia de la multiculturalidad y la vulnerabilidad del grupo gitano, cuya tutela puede — dentro de determinados márgenes discrecionales—implicar una aplicación más flexible de las leyes.

En relación con este último tipo de argumento, la sentencia Muñoz Díaz c. España se refiere directamente al caso Chapman c. Reino Unido y vuelve a proponer exactamente los mismos párrafos extraídos de dicha sentencia. ${ }^{16}$ Podemos observar entonces cómo el TEDH ha ido haciendo suya una doctrina que, en cuanto a tutelas de culturas minoritarias, asume una postura típica de la filosofía que

16 TEDH Muñoz Díaz c. España (2009). Párrafos relativos al caso Chapman contra Reino Unido:

«El TEDH observa, a este respecto, que surge en el seno de los Estados contratantes del Consejo de Europa un consenso internacional para reconocer las necesidades particulares de las minorías y la obligación de proteger su seguridad, su identidad y su modo de vida (ver, párrafo 33 anterior, especialmente el Convenio-marco del Consejo de Europa para la Protección de las Minorías), no sólo con el objetivo de proteger los intereses de las propias minorías sino también para preservar la diversidad cultural, lo que beneficia a la sociedad en su conjunto (Chapman c. Reino Unido [GC], n² 27238/95, §93, CEDH 2001-I).

El TEDH considera que, aunque la pertenencia a una minoría no exime de respetar las Leyes reguladoras del matrimonio, sí puede influir en la manera de aplicarlas. [...] la vulnerabilidad de la etnia gitana, por el hecho de constituir una minoría, implica prestar una atención especial a sus necesidades y a su propio modo de vida, tanto en el marco regulador válido en materia de ordenación como en el momento de la adopción de la decisión en casos particulares (ibídem $\$ \S 76,80,84$, Chapman, anteriormente citada $\S 96,[\ldots] »$. 
subyace las «acciones positivas» (del inglés affirmative action), ${ }^{17}$ que justifican un trato formalmente desigual con el objetivo de lograr una igualdad sustancial. ${ }^{18}$

\section{Las repercusiones de la jurisprudencia del TEDH sobre las sentencias del TC}

Mientras a lo largo de las últimas décadas el TC ha desarrollado una jurisprudencia destacada en cuanto al derecho a la igualdad (art. 14 CE) en asuntos de discriminación de género (SSTC 128/1987, $12 / 2008,59 / 2008$ ) y en temas relacionados con discapacidades físicas y mentales (STC 269/1994), no puede predicarse lo mismo con respecto a la discriminación por motivos étnicos o raciales (Rey Martínez y Giménez Glück 2010, 11). En esta sección, dicha cuestión se evaluará a la luz de las decisiones del TEDH para establecer cuál ha sido la influencia de las sentencias de Estrasburgo sobre las resoluciones del TC nacional.

El caso Williams (STC 13/2001) es de particular interés en materia de discriminación racial en el ámbito de los cuerpos y fuerzas de seguridad del Estado. Analizando esta sentencia, se entiende claramente cómo el Alto Tribunal en aquella ocasión legitimó el uso del criterio racial como potencial indicador de ilegalidad con el fin de respaldar la lucha contra la inmigración ilegal. En la sentencia

\footnotetext{
${ }^{17}$ En cuanto a este segundo tipo de argumentación, Rey Martínez (2012, 313-314) opina que, en realidad, el Tribunal cometió un error conceptual al indicar que la razón de la concesión de la pensión se basaba en una aplicación más flexible de la ley matrimonial. De hecho, según este autor, no se le trató en absoluto mejor a la demandante; más bien, simplemente se le reconoció lo que anteriormente el TC le había reconocido a una viuda en su misma situación, pero casada por el rito católico (véase STC 199/2004).

18 Las implicaciones conceptuales de este punto son, sin duda, significativas y es importante que la jurisprudencia recalque estos temas. De todos formas, en el contexto legislativo, hay que decir que si bien, tanto en España como en Europa, se han aprobado reformas de acción positiva en relación con la raza y el origen étnico (véase, por ejemplo, la Ley de 30 de diciembre de 2003), hasta el momento, la creación de este tipo de medidas no ha sido dirigida principalmente a la lucha contra la discriminación racial, sino, más bien, han favorecido a otros sectores considerados tradicionalmente más vulnerables en determinados contextos, como las mujeres en el campo laboral (véase la Ley 62/2003; Díez Picazo 2013, 194-197).
} 
13/2001 del día 29 de enero, de hecho, el TC se pronunció sobre la demanda de amparo de la señora Williams, ciudadana española, quien, después de haber agotado la vía interna, se dirigió a este Tribunal alegando, entre otros asuntos, que había sido discriminada por ser de raza negra cuando, en la tarde del 6 de diciembre de 1992, en la estación de trenes de Valladolid, un policía le pidió el carnet de identificación. Williams iba acompañada de su hijo y de su esposo, el señor Calabuig-Paris (de raza blanca). El policía sólo le pidió a la señora Williams que se identificara, no preguntó por los documentos de los otros miembros de su familia, ni por los de ningún otro pasajero en la estación. Cuando la señora Williams preguntó el porqué de este control tan específico hacia la única persona de raza negra en la estación, el policía le dejó entender que, debido a su apariencia, habría podido ser un inmigrante ilegal y que, por eso, necesitaba constatar la regularidad de su carnet de identidad (STC 13/2001, antecedente 3, p. 17).

El TC desestimó la demanda de Williams alegando que el comportamiento del representante de los cuerpos y fuerzas de seguridad del Estado estaba legitimado a raíz de la aplicación del régimen de extranjería, que exige que los extranjeros lleven consigo un permiso válido para comprobar su permanencia legal en el país (art. 72.1 del entonces vigente Reglamento de ejecución de la Ley Orgánica 7/1985). Por esta razón, según el TC, no fue ni ilógico ni discriminatorio que el agente de las fuerzas armadas usara el criterio racial o el "perfil étnico» como "carácter indiciario de una mayor probabilidad de que la interesada fuese extranjera» (STC 13/2001, p. 21), ya que el uso de la referencia étnica-racial con carácter descriptivo no es en sí un acto discriminatorio (cf. STC 126/1986). Además, el TC respaldó su decisión indicando que, «de hecho, los requerimientos de identificación en función de las apariencias, que permitían razonablemente presumir la condición de extranjeros de determinadas personas, hicieron posible que la actividad de la Brigada Móvil de Valladolid diera lugar a la localización de 126 extranjeros en situación ilegal durante 1992» (STC 13/2001, § 9). 
Al haber sido admitido que la identificación de la señora Williams se había fundado en el perfil étnico o racial, no fue necesario investigar el asunto ni implementar el esquema de inversión de la prueba propuesto por primera vez en la sentencia del TEDH Nachova y otros c. Bulgaria (2005) para mostrar potenciales casos de discriminación racial. De hecho, una lectura atenta de la resolución del TC permite notar que no hay referencias no sólo a este caso, sino tampoco a ninguna sentencia del TEDH en relación con asuntos de discriminación.

La decisión del TC en esta ocasión no fue unánime y que hubo un juez que disintió de la mayoría. Es el caso de la opinión contraria del magistrado Diego González Campos, quien indicó cómo, a su manera de entender la Constitución, un criterio de identificación basado exclusivamente en la pertenencia de una persona a un determinado grupo racial resultaría absolutamente prohibido por el art. 14 CE. Además, el juez subrayó que un sistema de ese tipo ya no es practicable en una sociedad multirracial como España, donde coexiste un número significativo de personas de razas diferentes. El magistrado hizo notar de manera muy clara que implementar un criterio racial de ese modo llevaría a efectos negativos previsibles para la dignidad de las personas afectadas (extranjeras y españolas):

España, al igual que muchos Estados europeos, ya es una "sociedad multirracial", en la que convive un número no desdeñable de personas de otras razas. $Y$ estas personas son tanto extranjeros en una situación regular como nacionales españoles.

Un dato que, por sí sólo debe excluir la introducción de la raza como criterio de selección en el control de extranjeros, en atención a sus previsibles efectos negativos para la dignidad de las personas. Pues basta reparar, en relación con los extranjeros del primer grupo, que si pueden quedar sujetos a la posibilidad de reiterados controles por razón de la raza, con tales medidas no sólo se está afectando negativamente a un elemento de la identidad de las personas que su dignidad 
como tales exige que sea respetado, sino que se está frustrando el objetivo de integración de los extranjeros en la sociedad española. Y respecto a los segundos, puede conducir a una consecuencia no menos grave: que se produzca una discriminación entre nacionales por razón de la raza, también atentatoria a su dignidad personal, como a mi entender ha sucedido en el presente caso.

Esta afirmación es de particular interés, sobre todo a la luz de los retos que supone la creciente multiculturalidad que caracteriza tanto a la sociedad española a nivel nacional y como a toda Europa. La opinión discordante del magistrado Diego González Campos está en sintonía con la Comunicación núm. 1493/2006 de 27 de julio de 2009 del Comité de Derechos Humanos, que se pronunció sobre el caso Williams.

Debido a la imposibilidad económica de Williams de recurrir inmediatamente la STC 13/2001, más de cinco años después, cuando encontró el apoyo legal de una ONG, la demandante llevó el caso frente al Comité de Derechos Humanos de la ONU, que clasificó la actuación de la policía como contraria al art. 26 en conjunción con el art. 2.3 del Pacto Internacional de Derechos Civiles y Políticos (PIDCP) de las Naciones Unidas, ${ }^{19}$ alegando que el elemento racial no puede usarse como único indicio de una posible situación irregular en el país ${ }^{20}$. De esta manera, el Comité de Derechos Humanos (CDH) condenó al Gobierno español a pagarle a Williams los gastos procesales más los daños morales y psicológicos que le causó dicha acción discriminadora. Además, pidió al país que le ofreciera una disculpa pública y que adoptase medidas oportunas para que situaciones de este tipo no volvieran a repetirse ${ }^{21}$. Hasta la fecha,

\footnotetext{
${ }^{19}$ Asamblea General de las Naciones Unidas. Pacto de Derechos Civiles y Políticos de las Naciones Unidas, firmado en Nueva York el 16 de diciembre de 1966. Disponible en: https://www.coe.int/es/web/compass/the-international-covenant-on-civil-andpolitical-rights

20 Suiza. Naciones Unidas, Comité de Derechos Humanos: Comunicación núm. 1493/2006 de 27 de julio de 2009, p. 10.

${ }^{21}$ Ibídem, pp. 9-11.
} 
España no ha cumplido completamente con todo lo ordenado por el $\mathrm{CDH}$. De hecho, como es bien sabido, las opiniones de los órganos de control creados por el PIDCP tienen valor cuasi-judicial, y entonces son resoluciones que por lo general no obligan formalmente a ningún Estado firmante a obedecer a su contenido decisional. Por eso, si bien la señora Williams recibió una carta de disculpas del Gobierno español, el Estado nunca se disculpó públicamente, y no la indemnizó por la discriminación sufrida, como indicaba la opinión del $\mathrm{CDH}$ (García Añón et al. 2013, 61-73).

El 30 de junio de 2016 se interpuso una demanda de amparo ante el TC por un caso similar al de Williams (SOS Racisme, p. 5). Sin embargo, la demanda no fue admitida por el Alto Tribunal (SOS Racisme, p. 6). Por tanto, no hay una doctrina jurisprudencial en el ámbito del TC sobre este tipo de discriminación. El caso en cuestión es el del señor Muhammad, ciudadano pakistaní con permiso de residencia en España desde 2005, quien el día 29 de mayo de 2013 fue parado e identificado por la policía de Barcelona. Cuando el señor Muhammad le preguntó al oficial policial si la razón del control se basaba en su apariencia y perfil racial, el policía, aparentemente, le contestó: «Sí, porque eres negro y punto» (SOS Racisme, p. 1).

La víctima no logró obtener justicia a través de la vía ordinaria y el TC no admitió su recurso de amparo por falta de trascendencia constitucional. El día 5 de mayo de 2017 interpuso así una demanda frente el TEDH el cual hasta la fecha no se ha pronunciado sobre el asunto (Open Society Foundations). Es interesante observar cómo, a lo largo de los varios juicios internos, la defensa se ha apoyado en la STC 13/2001, arguyendo que el TC respalda la identificación por perfil étnico-racial (SOS Racisme, pp. 4, 13, 15). De todas formas, a raíz de la Comunicación núm. 1493/2006 de 27 de julio de 2009 del CDH, sabemos que dicha práctica no está permitida. Parece entonces probable que el TEDH se pronuncie sobre este caso en sintonía con la ONU, sobre todo a la luz de algunas sentencias recientes sobre casos parecidos que involucran a otros países europeos (Ciorcan y otros $c$. 
Rumanía 2015; Boaca y otros c. Rumanía 2016; Grigoryan y Sergeyeva c. Ucrania 2017; Stefanou c. Grecia 2010).

La falta de recepción por parte del TC de la jurisprudencia del TEDH en asuntos de discriminación racial por perfil étnico se refleja también en la decisión de este Tribunal sobre el caso B.S., cuyo recurso fue desestimado el 14 de abril de 2008 por falta de contenido constitucional (STEDH B.S. c. España 2012, 6). Como vimos anteriormente, el caso fue apelado sucesivamente ante al TEDH, que condenó al Estado español por no haber llevado a cabo las medidas investigativas requeridas cuando se aplica el mecanismo probatorio de la inversión de la carga de la prueba (Nachova y otros $c$. Bulgaria 2005). De hecho, esta falta de investigación interna a las fuerzas armadas se dio a pesar de que las afirmaciones de la señora B.S. se fundasen en indicios muy concretos, como los documentos médicos que indicaban la presencia de lesiones.

Por otra parte, tradicionalmente el TC ha sido muy sistemático a la hora de condenar actos racistas y xenófobos disfrazados de libertad de expresión ideológica, por lo menos desde la histórica sentencia sobre el caso Friedman (STC 214/1991), relativo a una superviviente de los campos nazis de concentración de la Segunda Guerra Mundial, quien demandó al señor Degrelle, un exgeneral belga de las SS quien vivía bajo asilo político en España, por sus declaraciones negacionistas del Holocausto al periódico Tiempo y a la TVE en julio de 1985.

En la sentencia del TC 214/1991, del 11 de noviembre, el Alto Tribunal imputó una connotación racista y antijudía a las afirmaciones de Degrelle y consideró que podían verse como una incitación al odio racial y que atentaban contra el honor de toda la comunidad judía. Por esta razón, indicó que ataques de este tipo, basados en un discurso de odio, no podían ampararse ni bajo el manto de la libertad de ideología, ni bajo el de la libertad de expresión:

El odio y el desprecio a todo un pueblo o a una etnia (a cualquier pueblo o a cualquier etnia) son incompatibles con 
el respeto a la dignidad humana [...] Por lo mismo, el derecho al honor de los miembros de un pueblo o etnia, en cuanto protege y expresa el sentimiento de la propia dignidad, resulta, sin duda, lesionado cuando se ofende y desprecia genéricamente a todo un pueblo o raza, cualesquiera que sean [...]. En este sentido, [...] el requisito constitucional de la veracidad objetiva no opera como límite en el ámbito de las libertades ideológica y de expresión, tales derechos no garantizan, en todo caso, el derecho a expresar y difundir un determinado entendimiento de la historia o concepción del mundo con el deliberado ánimo de menospreciar y discriminan [...] a personas o grupos por razón de cualquier condición o circunstancia personal [...].

La sentencia Friedman ha tenido repercusiones significativas en la jurisprudencia del TC. Así, se encuentra sistemáticamente en los fundamentos jurídicos de los casos posteriores para indicar los límites del derecho a las libertades de ideología y expresión (SSTC 190/1992, 240/1992, etc.). En cuanto a asuntos de discriminación racial, el TC en la sentencia Williams se refiere explícitamente al caso Friedman para indicar los esfuerzos que dicho Tribunal ha llevado a cabo para luchar contra actos xenófobos y racistas protegidos bajo el escudo de la libertad de pensamiento (STC 13/2001, FJ 7).

También en la STC 235/2007 encontramos una colisión entre la libertad ideológica y de expresión y la prohibición de discriminación racial. En este caso, el TC hizo explícita referencia al caso Friedman para condenar a Varela Geis, el dueño de una librería neo-nazi de Barcelona, acusado de distribuir material bibliográfico negacionista del genocidio judío.

Como vimos en la sección 2, este caso fue llevado sucesivamente frente al TEDH, que el 5 de marzo de 2013 (STEDH Varela Geis $c$. España 2013), sin entrar en el asunto de la prohibición de discriminación, dictó un veredicto contra España en el cual estableció que, debido a fallos en el proceso, se había violado la plena capacidad de defensa de Varela Geis (art. $6 \mathrm{CEDH}$ ). Hasta ahora la sentencia del 
TEDH en el caso Varela Geis ha tenido efectos relativamente limitados sobre las sentencias posteriores del TC. Solamente en una ocasión el Alto Tribunal se ha referido a dicho caso. Se trata de la sentencia del TC 172/2016, en la que se hace referencia al asunto Varela Geis c. España para ofrecer un ejemplo de un caso de indefensión parcial. En cambio, la sentencia del TEDH en Jersild $c$. Dinamarca-que concierne, como ya vimos, al tema del odio racial en los medios de comunicación - tuvo un impacto más significativo en el sistema nacional y ha sido señalada por el TC en los fundamentos jurídicos de varias sentencias (SSTC 11/1998, 134/1999, 139/2007, 12/2012, 176/2013). En todos estos casos, se ha citado más que nada para identificar los límites entre el derecho de información (art. 20 CE) y otros derechos potencialmente contrastantes, como, por ejemplo, el derecho al honor, a la intimidad y a la propia imagen (art. $18 \mathrm{CE}$ ).

En particular, en varias ocasiones, se ha recordado que, en línea con la sentencia del TEDH en el caso Jersild c. Dinamarca, no se puede imputarles a los periodistas la culpa por comunicar enunciados potencialmente ofensivos si los medios de transmisión solo se limitan a reportarlos, manteniendo una posición neutral, como nos recuerda la sentencia del TC 134/1999 del 15 de julio de 1999 cuando afirma que:

[...] si el medio de comunicación cumple con [el] deber de diligencia, prueba de su neutralidad, el responsable de cuanto se diga en las declaraciones reproducidas será su autor material, esto es, quien las hace, pero no quien las reproduce [...] (STC 3/1997, STEDH, asunto Jersild, de 23 de septiembre de 1994).

Otro aspecto de la sentencia Jersild c. Dinamarca que ha sido recibido por el TC es que es contrario a la democracia silenciar las opiniones políticas ajenas, aunque puedan ser contrarias al sentido común o a la manera de ver las cosas por la mayoría de los ciudadanos: 
[...] la libre difusión de información y la expresión en libertad de ideas u opiniones -aun cuando sean chocantes, molestas o incluso inquietantes - constituyen fundamentos esenciales de la sociedad democrática y condiciones primordiales del desarrollo individual y del progreso colectivo [entre muchas, Sentencias del TEDH [...] (22 de agosto de 1994 asunto Jersild, \$37) [...J) (STC 134/1999).

Aun así, según el TC, esta lógica encuentra sus límites en la difusión de ideas racistas que puedan lesionar el honor de una determinada comunidad y fomentar sentimientos xenófobos y de odio hacia aquella, así como podemos deducir de la lectura de la sentencia del TC 235/2007 (caso Varela Geis), en la cual el TC hace varias referencias al caso Friedman:

El comportamiento cuestionado, en tanto tipificado como delictivo por el art. 607.2 CP, es la mera difusión de ideas o doctrinas que nieguen o justifiquen la existencia de hechos históricos que han sido calificados de genocidio. La Sala estima evidente el conflicto de tal tipificación con el derecho consagrado en el art. 20.1 CE. Sobre este derecho recuerda la doctrina sentada por este Tribunal en las SSTC 214/1991, de 11 de noviembre, [...] en el sentido de considerar que ofrece cobertura a las opiniones subjetivas e interesadas sobre determinados hechos históricos, por muy erróneas o infundadas que resulten, que no supongan un menosprecio a la dignidad de las personas o un peligro para la convivencia pacífica entre todos los ciudadanos.

En cuanto al último aspecto de la discriminación racial tratado en este estudio, es decir, la tutela de la igualdad sustancial de los grupos minoritarios, existe una sentencia del TEDH que tuvo repercusiones mediáticas significativas en España y que, en algunas ocasiones, ha sido mencionada en la jurisprudencia del TC. Se trata del caso Muñoz Díaz, que, como vimos en la sección 2, condenó España a pagarle la pensión de viudedad a una ciudadana española casada por el rito gitano, no reconocido formalmente válido en el país. 
La razón dada en este veredicto es que, en situaciones parecidas, como el caso de un matrimonio celebrado por el rito católico, pero no inscrito en el Registro Civil, el TC había concedido la jubilación a la viuda bajo el principio de buena fe.

En una sociedad cada vez más multicultural y multirracial como la española, es probable que con el tiempo aumenten las reclamaciones de determinados derechos por parte de varios grupos minoritarios, que pidan igualdad sustancial "ante la ley" y "en la ley" (Beckwith y Jones 1997). El precedente del caso Muñoz Díaz ya ha tenido algunas repercusiones significativas en este sentido. En particular, dos miembros de grupos minoritarios (uno por fe religiosa y el otro por orientación sexual), han solicitado igualdad de trato frente el sistema de seguridad social en cuanto a la posibilidad de recibir la pensión de la pareja difunta.

La sentencia del TC 194/2014 del $1^{\circ}$ de diciembre de 2014 se refiere al caso del señor Bassirou Sene Sene quien interpuso una demanda frente al TC reclamando la pensión de viudedad tras el fallecimiento de su esposa, con la que había contraído matrimonio a través del rito islámico. El rito islámico, en sí, no representa ningún problema, porque está reconocido por España. La razón del pleito radicaba en el hecho de que su matrimonio se había celebrado sin que existiera el certificado de capacidad matrimonial pertinente, de modo que nunca se inscribió en el Registro Civil, y, por lo tanto, la administración pública y todos los tribunales ordinarios frente a los cuales se interpuso la demanda se negaron a conceder dicha pensión de viudedad. En apoyo de su pretensión, Bassirou Sene Sene citó también los casos, ya mencionados, del rito católico no inscrito, en el cual el TC sí había concedido la pensión a la viuda (STC 199/2004), y la sentencia del TEDH Díaz Muñoz, alegando que ambas situaciones eran semejantes a la suya.

El TC decidió desestimar el recurso de Sene Sene alegando que los casos citados, en realidad, presentaban una gran diferencia con respecto del suyo. Dicha discrepancia consistiría en que en ambos 
casos la jubilación finalmente se concedió porque existían pruebas indicadoras de que el Estado en otras circunstancias, a lo largo de dichos matrimonios, había, de alguna manera, reconocido la validez de dichas uniones, fomentando así la creencia en buena fe de los cónyuges de que su unión sí estaba válidamente reconocida por España. Por ejemplo, en el caso de la Sra. Díaz Muñoz, a lo largo de su vida de casada, el Estado le otorgó el libro de familia y el título de familia numerosa. En cambio, en el caso del Sr. Sene Sene, España nunca habría reconocido la validez del matrimonio, así que no hay prueba de que el Estado hubiese inducido al Sr. Sene Sene a pensar que su unión fuese regular.

El otro episodio que se ha presentado frente al TC en relación con la sentencia Díaz Muñoz concierne al señor Aldeguer Tomás, el miembro sobreviviente de una pareja homosexual que, debido a la imposibilidad en España de casarse entre personas del mismo sexo antes de 2005, nunca pudo unirse en matrimonio con el difunto, quien falleció en 2003. Aldeguer Tomás reclamó su derecho a la pensión de viudedad alegando que, mientras su pareja estaba viva, nunca pudieron casarse, porque el ordenamiento español no contemplaba la boda homosexual. En apoyo de su pedido, el demandante indicó que, cuando se aprobó el divorcio en 1981 en España (Ley 13/1981), a los heterosexuales que convivían con otra persona sin haber podido casarse con ella (por no haber podido divorciarse de la pareja anterior), sí se les otorgó explícita y legalmente el derecho a dicha pensión.

Además, en la demanda de Aldeguer Tomás se hizo referencia explícita a los casos ya mencionados de la sentencia del TC 199/2004 y la sentencia del caso Díaz Muñoz c. España, en los cuales a las viudas finalmente se les concedió la pensión del esposo difunto. Según el demandante, entonces, se habría producido una discriminación por orientación sexual, en cuanto en su caso se le negaba el derecho a la pensión, derecho que, en cambio, sí se les había reconocido a los heterosexuales en situaciones semejantes: a los que no se habían 
casado por no poder divorciarse de la pareja precedente, y a los casados en buena fe sin haber registrado el matrimonio.

Mediante una resolución emitida el 11 de febrero de 2009, el TC declaró inadmisible el recurso de Aldeguer Tomás, indicando que el demandante no había justificado de manera suficiente la especial trascendencia constitucional del asunto. La demanda se interpuso entonces frente al TEDH el 22 de junio de 2009. El 18 de octubre de 2013 el Tribunal le comunicó la demanda al Gobierno de España. Finalmente, la sentencia se dictó el 17 de mayo de 2016 y en ella el TEDH señaló que el art. $14 \mathrm{CEDH}$ no se había violado porque las situaciones comparadas (parejas heterosexuales v. parejas homosexuales) no eran absolutamente análogas. La diferencia se fundamentaría en que:

las parejas homosexuales no podían casarse en absoluto antes de la entrada en vigor de la Ley 13/2005, mientras que las parejas heterosexuales podían hacerlo, pero no podían ejercer ese derecho ya que el divorcio era ilegal.

La razón por la cual el TEDH ve una diferencia sustancial entre dos situaciones tan parecidas como estas, donde esencialmente un obstáculo legal impide tanto a las parejas heterosexuales como a las homosexuales casarse, es que la ley 30/1981, que explícitamente otorgaba el derecho a la pensión a los miembros sobrevivientes de tales parejas, tenía el fin específico de proporcionar una solución "provisional y extraordinaria» en un contexto histórico en el que «la obtención del derecho a una pensión por trabajo remunerado no estaba distribuida equitativamente entre ambos sexos, ya que las mujeres estaban laboralmente infrarrepresentadas» .

Según el TEDH, entonces, habría una diferencia sociohistórica entre las dos situaciones que le conferiría al país un margen de decisión más amplio porque las autoridades locales estarían en mejor posición que un tribunal internacional para apreciar un asunto tan complejo «que además tiene implicaciones financieras considerables». Esta sentencia del $\mathrm{TEDH}$ ha sido recientemente 
mencionada por el TC para no admitir a trámite una cuestión de inconstitucionalidad relativa a una pareja de mujeres homosexuales, quienes no pudieron hacer uso de determinadas ventajas fiscales relacionadas con el matrimonio porque legalmente no pudieron casarse hasta 2005. En esta ocasión, como en el caso Aldeguer Tomás, el TC no admitió a trámite la cuestión, indicando que dicha problemática no tenía relevancia constitucional por haberse resuelto con anterioridad (en la sentencia del TEDH en Aldeguer Tomás c. España).

En esta resolución, no faltaron voces discordantes. Se trata del voto particular del magistrado Juan Antonio Xiol Ríos, al que se adhirieron la Magistrada Adela Asua Batarrita y el Magistrado Fernando Valdés Dal-Ré, quienes indicaron que, según su manera de ver el asunto, esta cuestión debería haberse admitido, por no existir doctrina constitucional en el ámbito tributario sobre temas de discriminación de los contribuyentes unidos de hecho ante la concesión de posibles beneficios fiscales por razón matrimonial. El Magistrado Xiol Ríos, además, invitó al Alto Tribunal a una interpretación del texto constitucional de acuerdo con una lectura igualitaria que esté más al paso con los tiempos y, entonces, con una sociedad más abierta y multicultural.

\section{Conclusiones}

España, a la par de otros países europeos, está pasando por un proceso de rápida evolución sociocultural, debido, en parte, a fenómenos como la globalización y la integración europea. El resultado de este proceso es un contexto social que tiende a ser cada vez más multiétnico y multirracial, donde muy a menudo nos encontramos frente a nuevos retos culturales y de integración. Este estudio ha procurado prestar atención a dicha problemática desde una perspectiva jurisprudencial. 
El gran reto de la multiculturalidad consiste en ser capaces de construir sociedades multiétnicas y democráticas, que sepan respetar los derechos humanos, fomentando, al mismo tiempo, la inclusión de los grupos minoritarios (Retortillo Osuna et al. 2006, 125). Dentro de este contexto, el papel del TEDH y de los tribunales constitucionales nacionales en la defensa de los derechos humanos y en la garantía del principio de igualdad y prohibición de la discriminación es crucial, así como una adecuada interlocución entre dichos órganos. Así, el análisis que se ha realizado acerca de la influencia de las resoluciones del TEDH sobre las sentencias del TC permite ofrecer, dentro de lo posible, observaciones que pueden servir como punto de partida para avanzar en la solución de algunos de los problemas existentes en esta materia y para contribuir en la construcción de una sociedad más incluyente, en línea con los retos que se han mencionado.

La evaluación de la casuística relativa al principio de igualdad en el contexto de la prohibición de discriminación racial se ha concentrado en tres ejes principales: el comportamiento de las fuerzas armadas del Estado, la información transmitida por los medios de comunicación, y la jurisprudencia a tutela de las minorías.

En cuanto a la relación entre los cuerpos y fuerzas de seguridad del estado, los datos evaluados sobre el comportamiento del TC en este frangente nos indican que el Alto Tribunal no ha sido muy receptivo a la jurisprudencia del TEDH. Hay que esperar que con el tiempo se vaya creando una jurisprudencia constitucional sobre casos de discriminación por perfil étnico o racial y sobre la importancia de la inversión de la carga de la prueba. Habría también que esperar que a nivel europeo el Tribunal de Estrasburgo estableciera, a través de sus sentencias, criterios no discriminatorios para luchar contra la inmigración ilegal. El TC en el caso Williams indicó que la raza podía considerarse como indicador de «mayor probabilidad de que la interesada fuese extranjera» (STC 13/2001). Este criterio puede parecer injusto y discriminatorio, pero no es completamente irracional $\mathrm{u}$ objetivamente no justificable. Para facilitar el trabajo de las fuerzas públicas y evitar futuros conflictos, el 
Tribunal de Estrasburgo podría establecer los límites «máximos y mínimos» (Carmona Cuenca 1994, 284) dentro de los cuales se pueda proceder al control de la identidad de personas sin que este control sea completamente al azar y sin que se base exclusivamente en las apariencias físicas.

El segundo aspecto de la discriminación racial que se ha tomado en consideración se ha enfocado sobre el discurso racista en los medios de comunicación. Vimos cómo el TEDH ha desarrollado una doctrina que esencialmente se ha basado en identificar los límites entre la libertad de expresión (art. 10 CEDH) y el principio de igualdad (art. $14 \mathrm{CEDH}$ ). Por su parte, el TC en casos de ese tipo ha condenado sistemáticamente los episodios racistas disfrazados de actos de libertad de opinión. El Alto Tribunal ha recibido la doctrina Jersil, pero parece citarla principalmente para identificar los límites entre libre expresión y otros derechos (no necesariamente relacionados con la prohibición de discriminación racial), como, por ejemplo, el derecho al honor, a la intimidad y a la propia imagen (art. $18 \mathrm{CE}$ ).

Finalmente, el último aspecto de la discriminación racial que se ha examinado es la tutela de los grupos minoritarios a través de una jurisprudencia que intente proteger a las mencionadas categorías proveyéndolas de una igualdad sustancial y respetando sus diferentes costumbres y estilos de vida. Un caso que tuvo repercusiones mediáticas significativas en España es la sentencia Muñoz Díaz (STC 235/2007). Esta sentencia, como vimos, sirvió de precedente para que otros grupos minoritarios reclamaran el mismo derecho a la seguridad social. En ambos casos, Aldeguer Tomás c. España (pareja homosexual) y Sene Sene (pareja casada por el rito islámico), las pensiones fueron denegadas. El dato más indicativo, de todas formas, es que el simple planteo de estas demandas frente al TC es síntoma de una sociedad que está cambiando de manera relativamente rápida en una dirección más abierta y multicultural.

Esta tendencia innovadora de la sociedad no siempre ha tenido un desarrollo paralelo en ciertas sentencias del TC. Por tanto, el Alto 
Tribunal debe avanzar en este sentido con una perspectiva que esté más al paso con los tiempos. Eso es lo que manifestó el magistrado Xiol Ríos en su voto discordante frente al caso de un asunto tributario reclamado por una pareja homosexual en el Auto 129 de 21 de junio de 2016 cuando dijo:

[Hay que] interpretar la Constitución de manera más acorde con la realidad social del tiempo en que se aplica: hay que tener en cuenta no solo el texto de la Constitución, sino las glosas que la vida ha escrito sobre ella (Felix Frankfurter). En mi opinión, resoluciones como la ahora dictada no contribuyen a reforzar la impresión de que el Tribunal esté avanzando en este insoslayable camino.

La investigación llevada a cabo en este estudio nos indica que la discriminación racial tiene muchas facetas, y no se puede analizar "en bloque”. Si por un lado el TC se ha demostrado muy receptivo hacia la jurisprudencia del TEDH e incluso proactivo en eliminar determinados aspectos de esta problemática (casos de discriminación racial en los medios de comunicación), por otra parte, hay que esperar un mayor esfuerzo en la recepción de la doctrina del TEDH —por ejemplo, en temas relacionados con la discriminación racial en el contexto de los cuerpos y fuerzas de seguridad del Estado-. El razonamiento de Xiol Ríos conlleva un mensaje muy poderoso, que seguramente encontrará un campo de aplicación en expansión en el futuro para los varios aspectos étnico-raciales y multiculturales en los cuales la jurisprudencia del Alto Tribunal no parece aún haberse consolidado.

Al cambiar la sociedad cambia también la interpretación de su derecho. La cuestión es ver hasta qué punto estos dos procesos van de forma paralela. Las jurisprudencias europea y española han evolucionado de manera significativa hacia sistemas más tolerantes y respetuosos de la diversidad étnica y racial. En general, se puede afirmar que se ha avanzado mucho en este sentido, y que seguramente todavía queda mucho por avanzar. 


\section{Bibliografía}

\section{Doctrina}

Abella Vázquez, Carlos. 2003. "Globalización y multiculturalismo: $i$ son posibles las democracias multiculturales en la era del globalismo?" Scripta Nova 7: 133-156.

Abrisketa Uriarte, Joana. 2015. "La discriminación racial: Un análisis comparado sobre el marco jurídico internacional y europeo." Revista electrónica de estudios internacionales 29: 1-36.

Beckwith, Francis J. y Todd E. Jones. 1997. “Introduction.” En Affirmative action: Social justice or reverse discrimination? dirigido por Francis J. Beckwith y Todd E. Jones, 9-20. Amherst, NY: Prometheus Books.

Berenguer Albaladejo, Cristina. 2010. "El principio de igualdad y no discriminación en relación con la pensión de viudedad y el 'matrimonio gitano'." Derecho privado y constitución 24: 109162.

Bouazza Ariño, Omar. 2003. "Respeto a la vida privada y protección del medio ambiente en la jurisprudencia del tribunal europeo de derechos humanos." Revista de Administración Pública 160: 167-202.

Briones Gómez, Rafael. 2007. “La integración del ‘otro’ en la emergente España multicultural.” Gazeta de Antropología 23: 114.

Carmona Cuenca, Encarnación. 1994. "El principio de igualdad material en la jurisprudencia del Tribunal Constitucional." Revista de estudios políticos 84: 265-285.

Cea D’Ancona, María Ángeles y Miguel S. Valles Martínez. 2011. Evolución del racismo y la xenofobia en España. Madrid: Ministerio de Trabajo e Inmigración.

Cremades García, Purificación. 2010. "La no discriminación en la exigencia de un rito matrimonial. A propósito de la sentencia del tribunal Europeo de Derechos Humanos de 8 de diciembre de 2009. Caso Muñoz Díaz contra España." Revista Europea de Derechos Fundamentales 16 (2): 329-347.

Díez Picazo, Luis María. 2013. Sistema de derechos fundamentales. Pamplona: Civitas. 
Esquivel Alonso, Yéssica. 2016. El discurso de odio en la jurisprudencia del Tribunal Europeo de Derechos Humanos. Cuestiones constitucionales 35: 3-44.

García Añón, José, Ben Bradford, José Antonio García Saez, Andrés Gascón Cuenca y Antoni Llorente y Ferreres. 2013. Identificación por perfil étnico en España. Informe sobre experiencias y actitudes en relación con las paradas policiales. Valencia: Tirant lo Blanch.

Kiska, Roger. 2012. "Hate speech: A comparison between the European Court of Human Rights and the United States Supreme Court jurisprudence." Regent University Law Review 25: 107-151.

Möschel, Mathias. 2014. Law, lawyers and race: Critical race theory from the US to Europe. Londres: Routledge.

Quesada Alcalá, Carmen. 2015. "La labor del tribunal europeo de derechos humanos en torno al discurso de odio en los partidos políticos: Coincidencias y contradicciones con la jurisprudencia española." Revista electrónica de estudios internacionales 30: 133.

Retortillo Osuna, Álvaro, Anastasio Ovejero Bernal, Fatima Regina Cruz Sousa, Benito Arias Martínez y Susana Lucas Mangas. 2006. "Inmigración y modelos de integración: Entre la asimilación y el multiculturalismo.” Revista universitaria de ciencia del trabajo 7: 123-139.

Rey Martínez, Fernando. 2008. "La sentencia del Tribunal Europeo de Derechos Humanos, de la Gran Sala, 'D. H. y otros contra República Chequia', de 13 noviembre de 2007." Direitos Fundamentais \& Justiça 2 (4): 61-65.

—. 2012. "La discriminación racial en la jurisprudencia del Tribunal Europeo de Derechos Humanos." Pensamiento Constitucional 17: 291-319.

Rey Martínez, Fernando y David Giménez Glück. 2010. Por la diversidad, contra la discriminación. Madrid: Fundación Ideas.

\section{Legislación}

España. Ley Orgánica 7/ 1985, de 1 de julio, sobre derechos y libertades de los extranjeros en España. Boletín Oficial del Estado, 3 de julio de 1985, núm. 158, pp. 20824-20829. 
España. Ley 62/2003, de 30 de diciembre, de medidas fiscales, administrativas y del orden social. Boletín Oficial del Estado, 31 de diciembre de 2003, núm. 313, pp. 46874-46992.

España. Real Decreto Legislativo 8/2015, de 30 de octubre, texto refundido Ley General de la Seguridad Social. Boletín Oficial del Estado, de 31 de octubre de 2015, núm. 261, pp. 103291-103519.

Estados Unidos de América. Asamblea General de las Naciones Unidas. Pacto de Derechos Civiles y Políticos de las Naciones Unidas, firmado en Nueva York el 16 de diciembre de 1966. Disponible en: https://www.coe.int/es/web/compass/theinternational-covenant-on-civil-and-political-rights

Italia. Convenio Europeo para la Protección de los Derechos Humanos y de las Libertades Fundamentales, adoptado por el Consejo de Europa en Roma, el 4 de noviembre 1950. Disponible en: http://www.echr.coe.int/Documents/Convention_SPA.pdf

Italia. Protocolo 12 del Convenio Europeo para la Protección de los Derechos Humanos y de las Libertades Fundamentales, adoptado por el Consejo de Europa en Roma, el 4 de noviembre de 2000. Disponible en:

http://www.derechoshumanos.net/Convenio-Europeo-deDerechos-Humanos-CEDH/2000Protocolo12ConvenioProteccionDerechosHumanosyLibertades Fundamentales.html

\section{Jurisprudencia}

España. Tribunal Constitucional (Pleno). Auto núm. 129/2016 de 21 de junio.

—. Sentencia núm. 12/2008 de 29 de enero.

—. Sentencia núm. 235/2007 de 7 de noviembre.

—. Sentencia núm. 59/2008 de 14 de mayo.

España. Tribunal Constitucional (Sala 1a). Sentencia núm. 11/1998 de 13 de enero.

—. Sentencia núm. 12/2012 de 30 de enero.

—. Sentencia núm. 126/1986 de 22 de octubre.

—. Sentencia núm. 134/1999 de 15 de julio. 
—. Sentencia núm. 139/2007 de 4 de junio.

—. Sentencia núm. 172/2016 de 17 de octubre.

—. Sentencia núm. 190/1992 de 16 de noviembre.

- Sentencia núm. 214/1991 de 11 de noviembre.

—. Sentencia núm. 235/2007 de 7 de noviembre.

—. Sentencia núm. 240/1992 de 21 de diciembre.

—. Sentencia núm. 269/1994 de 3 de octubre.

España. Tribunal Constitucional (Sala 2a). Sentencia núm. 128/1987 de 16 de julio.

—. Sentencia núm. 13/2001 de 22 de octubre.

-. Sentencia núm. 176/2013 de 21 de octubre

—. Sentencia núm. 194/2014 de 1 de diciembre.

—. Sentencia núm. 199/2004 de 15 de noviembre.

—. Sentencia núm. 3/1997 de 13 de enero.

Suiza. Naciones Unidas, Comité de Derechos Humanos:

Comunicación núm. 1493/2006 de 27 de julio de 2009.

Tribunal Europeo de Derechos Humanos (Gran Sala), Caso Beard contra Reino Unido. Sentencia de 18 de enero de 2001.

- Caso Chapman contra Reino Unido. Sentencia de 18 de enero de 2001.

- Caso Coster contra Reino Unido. Sentencia de 18 de enero de 2001.

—, Caso Lee contra Reino Unido. Sentencia de 18 de enero de 2001.

- Caso Nachova y otros contra Bulgaria. Sentencia de 6 de julio de 2005.

-, Caso D.H. y otros contra República Checa de 13 noviembre de 2007.

- Caso Smith contra Reino Unido. Sentencia de 18 de enero de 2001.

Tribunal Europeo de Derechos Humanos (Sección 1a), Caso Anguelova contra Bulgaria. Sentencia de 13 de septiembre de 2002. 
—, Caso B.S. contra España. Sentencia de 24 de julio de 2012.

- , Caso Bekos y Koutropoulos contra Grecia. Sentencia de 13 de diciembre de 2005

- Caso Jaloud contra Holanda. Sentencia de 20 de noviembre de 2014

-, Caso Jersild contra Dinamarca. Sentencia de 23 de septiembre de 1994.

- Caso Ognyanova y Chocan contra Bulgaria. Sentencia de 23 de febrero de 2006

Tribunal Europeo de Derechos Humanos (Sección 3a), Aldeguer Tomás contra España. Sentencia de 14 de junio de 2016.

- Caso Ciorcan y otros contra Rumanía. Sentencia de 6 de enero de 2015.

—, Caso Muñoz Díaz contra España. Sentencia de 8 de diciembre de 2009.

Tribunal Europeo de Derechos Humanos (Sección 4a), Caso Boaca y otros contra Rumanía. Sentencia de 12 de enero de 2016.

-, Caso Grigoryan y Sergeyeva contra Ucrania. Sentencia de 28 de marzo de 2017.

-, Caso Norwood contra Reino Unido. Sentencia de 16 de noviembre de 2004.

—, Caso Stefanou contra Grecia. Sentencia de 22 de abril de 2010.

—, Caso Varela Geis contra España. Sentencia de 5 de marzo de 2013.

-, Caso Willis contra Reino Unido. Sentencia de 11 de septiembre de 2002.

\section{Formatos electrónicos}

Instituto Nacional de Estadística 2017: Cifras de Población a 1 de enero de 2017. En: http://www.ine.es/prensa/cp_2017_p.pdf

Open Society Foundations: Litigation Zeshan Muhammad v. Spain. En: https://www.opensocietyfoundations.org/ litigation/zeshan-muhammad-v-spain

SOS Racisme: Demanda caso Zeshan Muhammad contra España. Disponible. En: www.sosracisme.org/wpcontent/uploads/2017/05/Zeshan-Muhammad-v.-Spain.pdf 